\begin{tabular}{|c|c|c|c|c|}
\hline JURNAL & VOLUME 1 & NOMOR 1 & HALAMAN 1-70 & $\begin{array}{r}\text { ISSN 2655-8823 }(p) \\
\text { ISSN - }(e)\end{array}$ \\
\hline
\end{tabular}

\title{
KONFLIK ANTARA PLTU INDRAMAYU II DENGAN WARGA MEKARSARI DILIHAT DARI TEORI KEBUTUHAN MANUSIA SIMON FISHER
}

\author{
Rosa Gamayanti \\ Mahasiswa Program Studi Kesejahteraan Sosial FISIP UNPAD \\ E-mail:gamayantirosa@gmail.com \\ Soni Akhmad Nulhaqim \\ Dosen Program Studi Kesejahteraan Sosial FISIP UNPAD \\ E-mail: soni.nulhaqim@unpad.ac.id
}

\begin{abstract}
ABSTRAK
Konflik merupakan salah satu bentuk dari permasalahan sosial yang ada di masyarakat. Konflik dapat terjadi dikarena berbagai macam hal. Salah satunya dikarenakan oleh kebutuhan manusia yang tidak terpenuhi atau adanya perebutan atas hak yang dimiliki oleh masing-masing pihak yang sedang berkonflik. Konflik yang terjadi di antara PLTU Indramayu II dengan warga Mekarsari merupakan salah satu contoh nyata akibat tidak terpenuhinya kebutuhan diantara pihak yang berkonflik serta adanya perebutan kepemilikan lahan diantara keduanya. Konflik yang terjadi tersebut dapat menimbulkan perpecahan, kekerasan, dan kerugian yang dapat dialami oleh kedua belah pihak. Berbagai macam upaya perlu dilakukan untuk menghentikan konflik tersebut. Salah satu langkah yang dapat dilakukan yaitu dengan mengadakan resolusi konflik untuk kedua pihak yang sedang berkonflik. Melalui resolusi konflik diharapkan pihak yang berkonflik dapat mencapai kesepakatan terbaik untuk memenuhi kebutuhan dasar semua pihak yang berkaitan.
\end{abstract}

Kata Kunci : Konflik, Kebutuhan Manusia, Resolusi Konflik

\section{ABSTRACT}

Conflict is a form of social problems that exist in society. Conflicts can occur due to various things. One of them is due to unmet human needs or the struggle for rights owned by each party in conflict. The conflict between the PLTU Indramayu II and the residents of Mekarsari is one concrete example of the lack of fulfillment of the needs of those in conflict and the struggle for land ownership between the two. The conflict that occurs can lead to divisions, violence, and losses that can be experienced by both parties. Various kinds of efforts need to be made to stop the conflict. One step that can be done is by holding conflict resolution for both parties in conflict. Through conflict resolution it is hoped that the conflicting parties can reach the best agreement to meet the basic needs of all parties concerned.

Keywords : Conflict, Human Needs, Conflict Resolution

\section{PENDAHULUAN}

Konflik merupakan suatu proses alami yang senantiasa terjadi di masyarakat. Selama di dalam masyarakat masih terjadi interaksi satu sama lain, maka kemungkinan untuk terjadi sebuah konflik di masyarakat akan selalu ada. Menurut Soerjono Soekanto (2006), konflik adalah proses dari setiap individu atau kelompok yang akan menggunakan segala cara termasuk ancaman atau kekerasan sebagai bentuk pertentangan terhadap lawannya. Konflik merupakan sesuatu yang sangat sensitif. Konflik dapat disebabkan oleh berbagai macam hal diantaranya seperti adanya perebutan kekuasaan, perbedaan sudut pandang ataupun pendapat, perbedaan agama, bahkan dapat disebabkan karena adanya hak yang tidak terpenuhi dengan baik seperti yang seharusnya. Konflik dapat terjadi kapan saja, dimana saja, dan melibatkan siapa saja. Baik di negara yang telah maju maupun negara 


\begin{tabular}{|c|c|c|c|c|}
\hline $\begin{array}{c}\text { JURNAL } \\
\text { KOLABORASI RESOLUSI KONFLIK }\end{array}$ & VOLUME 1 & NOMOR 1 & HALAMAN 1-70 & $\begin{array}{r}\text { ISSN 2655-8823 }(p) \\
\text { ISSN - }(e)\end{array}$ \\
\hline
\end{tabular}

yang masih berkembang keduanya samasama memiliki potensi untuk terjadi sebuah konflik di dalamnya.

Konflik yang terjadi di masyarakat dapat memberikan dampak negatif dan juga dampak positif. Dampak negatif misalnya ketika konflik yang terjadi berupa menjadi kerusuhan yang mengakibatkan kerusakan harta benda yang dimiliki oleh masyarakat. Berdampak positif apabila konflik yang terjadi bersifat membangun salah satunya dengan perubahan mindset atau pola pikir masyarakatnya ke arah yang lebih baik. Salah satu contoh konflik yang terjadi yaitu konflik antara PLTU Indramayu II dengan warga Mekarsari.

Konflik yang terjadi antara PLTU Indramayu II dengan warga Mekarsari ini disebabkan oleh adanya perebutan lahan antara pihak PLTU Indramayu II dengan warga Mekarsari mengenai lahan yang tadinya akan digunakan untuk membangun PLTU Indramayu II dikarenakan izin lingkungan pembangkit listrik ini melanggar UU karena dikeluarkan oleh Pemerintah Indramayu dimana seharusnya dikeluarkan oleh Pemerintah Jawa Barat sesuai UU No 23 / 2014 Tentang Pemerintah Daerah dalam sidang putusan hakim yang akhirnya dimenangkan oleh warga Mekarsari dalam sidang gugatan yang berlangsung di PTUN Bandung pada 6 Desember $2006^{1}$. Konflik yang terjadi semakin memanas ketika Polsek Patrol dan Polres Indramayu melakukan penangkapan terhadap beberapa warga Mekarsari dengan dugaan kriminalisasi yang dilakukan warga Mekarsari, dimana hal tersebut juga dipicu oleh adanya kesimpangsiuran informasi salah satunya mengenai kasus penghinaan lambang negara (Syahni, 2018).

Berdasarkan konflik yang telah dipaparkan sebelumnya penulis

${ }^{1}$ https://www.mongabay.co.id/2018/01/17/berkonflikdengan-pltu-indramayu-ii-berbuntut-penangkapanwarga-mekarsari-lapor-komnas-ham/ mengidentifikasi bahwa konflik yang terjadi memerlukan suatu upaya untuk mengatasi konflik dan meminimalisasi efek yang ditimbulkan dari konflik tersebut. Upaya yang telah dilakukan sebagai bentuk pemecahan masalah atas konflik yang sedang terjadi antara PLTU Indramayu II dengan warga Mekarsari yaitu dengan mendatangi Komisi Nasional HAM. Dengan mendatangi Komisi Nasional HAM warga berharap ketidakadilan yang terjadi dapat diluruskan serta untuk ikut serta menengahi dan mencari solusi terbaik atas konflik yang sedang terjadi.

\section{TINJAUAN PUSTAKA}

\section{A. Pengertian Konflik}

Menurut Soerjono Soekanto, konflik adalah proses dari setiap individu atau kelompok yang akan menggunakan segala cara termasuk ancaman atau kekerasan sebagai bentuk pertentangan terhadap lawannya. Kemudian pengertian konflik yang lain, konfllik adalah hubungan yang terjadi di antara dua pihak atau lebih (individu atau kelompok) yang memiliki atau yang merasa memiliki, sasaran-sasaran yang tidak sejalan (Simon Fisher : 2000).

\section{B. Teori Penyebab Konflik}

Ada beberapa Teori Penyebab Konflik yang terdapat dalam buku "Mengelola Konflik" Simon Fisher (2000) di antaranya adalah teori hubungan masyarakat, teori Negosiasi Prinsip, teori kebutuhan manusia, teori identitas, teori kesalahpahaman antar budaya, dan teori transformasi konflik.

Teori Kebutuhan Manusia akan digunakan untuk analisis fenomena yang dikaji teori mengemukakan bahwa konflik disebabkan kebutuhan dasar manusia meliputi fisik, mental dan sosial yang tidak terpenuhi. Kebutuhan itu terutama terkait 


\begin{tabular}{|c|c|c|c|c|}
\hline $\begin{array}{c}\text { JURNAL } \\
\text { KOLABORASI RESOLUSI KONFLIK }\end{array}$ & VOLUME 1 & NOMOR 1 & HALAMAN 1-70 & $\begin{array}{c}\text { ISSN 2655-8823 }(p) \\
\text { ISSN - }(e)\end{array}$ \\
\hline
\end{tabular}

dengan, keamanan, identitas, pengakuan, partisipasi, dan otonomi.

Sasaran teori kebutuhan manusia adalah : (a). Membantu pihak yang konflik untuk mengidentifikasi dan mengupayakan bersama kebutuhan mereka yang tidak terpenuhi, dan menghasilkan pilihan-pilihan untuk memenuhi kebutuhan-kebutuhan itu; (b).pihak yang berkonflik agar mencapai kesepakatan untuk memenuhi kebutuhannya.

\section{Resolusi Konflik}

Resolusi konflik adalah suatu upaya untuk menangani berbagai sebab konflik dan kemudian berusaha untuk membangun suatu hubungan baru yang bisa bertahan lama di antara pihak-pihak yang berseteru (Fisher et al : 2000). Dalam buku yang berjudul Mengelola Konflik terdapat beberapa istilah yang menunjukkan berbagai pendekatan untuk menangani konflik meliputi : (1). Pencegahan konflik, bertujuan untuk mencegah timbulnya konflik yang tegas; (2). Penyelesaian konflik, bertujuan untuk mengakhiri perilaku kekerasan melalui suatu persetujuan perdamaian; (3) Pengelolaan konflik, bertujuan untuk membatasi dan menghindari kekerasan dengan mendorong perubahan perilaku yang positif bagi pihakpihak yang terlibat; (4). Resolusi konflik, menangani sebab-sebab konflik dan berusaha membangun hubungan baru dan yang bisa tahan lama di antara kelompok-kelompok yang bermusuhan;

Transformasi konflik, mengatasi sumbersumber konflik dengan berusaha mengubah kekuatan negatif dari peperangan menjadi kekuatan sosial dan politik yang positif.

\section{METODE PENELITIAN}

Penelitian ini menggunakan jenis penelitian deskripsi dengan dengdekatan kualititatif tentang konflik yang terjadi antara PLTU Indramayu II dengan warga Mekarsari. Data yang digunakan adalah data sekunder. Data sekunder yang digunakan merupakan data sekunder yang dapat berasal dari hasil penelitian terdahulu, jurnal, artikel, maupun buku yang sudah diterbitkan.

\section{HASIL DAN PEMBAHASAN \\ Penyebab Konflik}

Konflik antara pihak PLTU Indramayu II dengan warga Mekarsari disebabkan oleh persoalan lahan yang akan digunakan untuk membangun PLTU Indramayu II. Disamping itu, pihak masyarakat menganggap izin lingkungan pembangkit listrik ini melanggar UU karena dikeluarkan oleh Pemerintah Indramayu, dimana seharusnya dikeluarkan oleh Pemerintah Jawa Barat sesuai UU. No 23 / 2014. Sidang putusan hakim yang yang berlangsung di PTUN Bandung pada 6 Desember 2006 memutuskan bahwa pihak warga Mekarsari memenangkan konflik lahan tersebut.

\section{Pemicu Konflik}

Peristiwa ini dipicu oleh adanya informasi yang yang kurang jelas tentang adanya penangkapan beberapa warga Mekarsari oleh Polres setempat dengan dugaan kriminalisasi yang dilakukan warga Mekarsari yang dipicu oleh kesimpangsiuran informasi salah satunya mengenai kasus.

Aktor yang Terlibat

- Warga yang berada di Desa Mekarsari dan 4 dusun lainnya di Kecamatan Patrol, Kabupaten Indramayu, Provinsi Jawa Barat.

- Pihak PLTU Indramayu II dan PT. PLN

- Polsek Patrol dan Polres Indramayu

- Komisi Nasional HAM

Dampak Lingkungan

- Penangkapan ikan menjadi lebih sulit

- Tanaman banyak yang menjadi tidak subur lagi

Dampak Kesehatan 


\begin{tabular}{|c|c|c|c|c|}
\hline $\begin{array}{c}\text { JURNAL } \\
\text { KOLABORASI RESOLUSI KONFLIK }\end{array}$ & VOLUME 1 & NOMOR 1 & HALAMAN 1-70 & $\begin{array}{r}\text { ISSN 2655-8823 }(p) \\
\text { ISSN - }(e)\end{array}$ \\
\hline
\end{tabular}

- Banyak anak kecil di Desa Ujung Gebang terkena penyakit pilek dan penyakit ISPA (Infeksi Saluran Pernapasan Akut)

- Adanya paparan polusi yang terjadi pada anak usia 2-7 tahun

Dampak Ekonomi

- Hilangnya lahan seluas 279 hektar yang biasa digunakan oleh para petani untuk bercocok tanam seperti cabe, bawang, sayur, hingga padi dimana itu merupakan mata pencaharian warga setempat.

\section{Resolusi Konflik}

Pengaduan yang dilakukan oleh warga Desa Mekarsari, Kecamatan Patrol, Kabupaten Indramayu, Jawa Barat kepada Komisi Nasional HAM agar dapat membantu dalam penyelesaian masalah yang ada sebagai respon dari penangkapan serta tuduhan tindakan kriminalisasi kepada pihak yang berwajib agar permasalahan tidak berlarut-larut dan segera menemukan titik terang sebagai solusi terbaik untuk pemecahan masalah yang tengah terjadi.

\section{PEMBAHASAN}

\section{Analisis Berdasarkan Teori Kebutuhan Manusia Simon Fisher}

Apabila konflik yang terjadi di antara kedua belah pihak yaitu antara warga yang berada di Desa Mekarsari dan 4 dusun lainnya di Kecamatan Patrol, Kabupaten Indramayu, Provinsi Jawa Barat dengan pihak PLTU Indramayu II dianalisis konflik tersebut sesuai dengan teori kebutuhan manusia. Teori kebutuhan manusia berasumsi bahwa konflik yang berakar dalam disebabkan oleh kebutuhan dasar manusia baik itu fisik, mental, dan sosial yang tidak terpenuhi atau dihalangi. Keamanan, identitas, pengakuan, partisipasi, dan otonomi sering merupakan inti pembicaraan.
Sasaran yang ingin dicapai dalam teori ini adalah:

1. Membantu pihak-pihak yang mengalami konflik untuk mengidentifikasi dan mengupayakan bersama kebutuhan mereka yang tidak terpenuhi, dan menghasilkan pilihan-pilihan untuk memenuhi kebutuhan-kebutuhan itu.

2. Agar pihak-pihak yang mengalami konflik mencapai kesepakatan untuk memenuhi kebutuhan dasar semua pihak atau pihak yang tengah berada di dalam konflik tersebut.

Asumsi yang terdapat dalam teori kebutuhan manusia selaras dengan konflik yang sedang terjadi antara warga di Desa Mekarsari tersebut dengan pihak PLTU Indramayu II dimana kebutuhan dasar akan mata pencaharian warga terganggu yaitu dimana lahan yang biasanya mereka pakai untuk bercocok tanam digunakan sebagai lahan untuk pembangunan PLTU Indramayu II itu sehingga perekonomian warga yang bersangkutan menjadi ikut terganggu pula serta dari segi kemananan warga juga belum terpenuhi karena beberapa warga ada yang dilaporkan kepada pihak yang berwajib dengan tuduhan yang sebenarnya tidak pernah dilakukan sama sekali oleh warga yang bersangkutan tersebut.

Pihak dari PLTU Indramayu II juga merasakan hal yang serupa. Pihak PLTU Indramayu II merasa bahwa kebutuhan dasarnya untuk pembangunan PLTU Indramayu II belum terpenuhi dikarenakan aturan yang dikeluarkan oleh pemerintah Indramayu telah sah atas ijin pembangunan tersebut namun kenyatannya ijin tersebut dianggap bermasalah. Ijin tersebut dianggap bermasalah karena aturannya bukan berasal dari pemerintah pusat yang akhirnya mengakibatkan kekalahan dalam proses persidangan dan akhirnya menimbulkan konflik. Selain selaras dikarenakan penyebab konfliknya teori kebutuhan dasar tersebut 
juga selaras dikarenakan sasaran dari teori kebutuhan dasar ini juga sesuai dengan konflik yang terjadi yaitu untuk membantu kedua belah pihak untuk memperoleh kebutuhan dasarnya masing-masing serta membantu agar pihak yang mengalami konflik mampu untuk mencapai kesepakatan untuk memenuhi kebutuhan dasar semua pihak atau pihak yang tengah berada di dalam konflik tersebut.

\section{KESIMPULAN DAN SARAN Kesimpulan}

Konflik merupakan suatu fenomena yang akan dan senantiasa ada di masyarakat. Konflik akan selalu ada di masyarakat selama interaksi antara satu individu dengan individu lainnya masih berlangsung. Konflik dapat terjadi dikarenakan berbagai macam perbedaan di mulai dari perbedaan pendapat, keyakinan, tujuan hingga berbagai perbedaan lainnya. Selain itu konflik juga dapat terjadi dikarenakan oleh tidak terpenuhinya hak-hak yang seharusnya dimiliki pihak yang bersangkutan dimana hak tersebut merupakan kebutuhan yang sangat penting seperti kebutuhan fisik, mental, sosial, hingga keamanan, dan pengakuan. Ada atau tidak tidaknya konflik bukan suatu hal yang utama melainkan bagaimana cara menyikapi konflik yang terjadi itulah hal yang terpenting. Salah satu upaya yang dapat dilakukan yaitu dengan bersama-sama melakukan resolusi konflik dengan berbagai pihak terkait untuk mencari solusi terbaik dari konflik yang tengah berlangsung.

Konflik yang terjadi antara PLTU Indramayu II dengan warga Mekarsari disebabkan oleh berbagai macam faktor penyebab yang sudah mengakar diantaranya yaitu faktor ekonomi, sosial, dan politik. Pihak dari warga Mekarsai tetap mempertahankan tanah yang selama ini telah diolah dan dijadikan sebagai lahan mata pencaharian mereka sehari-hari agar keberlangsungan hidup mereka jika dilihat dari sisi ekonomi dapat terus berlangsung dengan baik. Kemudian jika dilihat dari sisi sosial atau lebh tepatnya keadilan sosial warga Mekarsari juga akan terus mengupayakan dengan meminta tolong kepada Komisi Nasional HAM sebagai penengah sekaligus penegak keadilan karena jika dilihat dari sisi politik dalam hal ini polisi yang bertindak sebagai pihak berwajib tidak dapat berlaku secara adil dan cenderung memihak kepada PLTU Indramayu II dengan melakukan penangkapan kepada beberpa orang warga dengan tuduhan kriminalisasi yang sebenarnya tidak pernah terjadi.

\section{Saran}

Melihat banyaknya dampak negatif yang ditimbulkan dari adanya konflik yang terjadi antara PLTU Indramayu II dengan warga Mekarsari dilihat dari berbagai aspek sudah seharusnya para pemangku kepentingan ikut serta dalam penyelesaian konflik yang sedang terjadi tersebut. Berbagai macam elemen mulai dari masyarakat, pekerja sosial, organisasi sosial, hingga pemerintah seharusnya bahu membahu dalam menangani konflik yang ada di masyarakat Apabila setiap elemen dapat bekerja sama dengan baik maka konflik dapat lebih mudah untuk diatasi tidak banyak menimbulkan korban dan kerugian baik materil maupun non materil akibat adanya konflik. Dengan demikian kedamaian dan kerukunan akan senantiasa terjalin dalam kehidupan bermasyarakat, berbangsa, dan bernegara.

\section{DAFTAR PUSTAKA}

Fisher, Simon. 2001. Mengelola Konflik: Ketrampilan dan Strategi untuk Bertindak. Penerbit SMK Grafika Desa Putra. Jakarta.

Soerjono Soekanto. 2006. Sosiologi Suatu

Pengantar. Jakarta: Raja Grafindo

Persada. 


\begin{tabular}{|c|c|c|c|c|}
\hline $\begin{array}{c}\text { JURNAL } \\
\text { KOLABORASI RESOLUSI KONFLIK }\end{array}$ & VOLUME 1 & NOMOR 1 & HALAMAN 1-70 & $\begin{array}{r}\text { ISSN 2655-8823 }(p) \\
\text { ISSN - }(e)\end{array}$ \\
\hline
\end{tabular}

Pengertian Resolusi Konflik. https://www.definisimenurutparaahli.co $\mathrm{m} /$ pengertian-resolusi-konflik/

2017. 9 Pengertian Konflik Menurut Para Ahli.http://www.sumberpengertian.co/pe ngertian-konflik-menurut-para-ahli

Samiun, Ali. 2015. Pengertian Analisis Data, Tujuan dan Tekniknya. http:/www.informasiahli.com/2015/08/p engertian-analisis-data-tujuan-dantekniknya.html

$2010 . \quad$ Teori Konflik. https://imbang88.wordpress.com/2010/0 4/01/teori-konflik/

2017. Manajemen Konflik - Pengertian, Ciri, Tahapan, Tingkatan, Strategi dan Dampak Konflik. Diunduh dari https://www.pelajaran.id/2017/21/manaj emen-konflik-pengertian-ciri-tahapantingkatan-strategi-dan-dampakkonflik.html.

Syahni, Della. 2018. Berkonflik dengan PLTU Indramayu II Berbuntut Penangkapan, Warga Mekarsari Lapor Komnas HAM. Diunduh dari https://www.mongabay.co.id/2018/01/17 /berkonflik-dengan-pltu-indramayu-iiberbuntut-penangkapan-wargamekarsari-lapor-komnas-ham/ pada 23 Desember 2018. 